\title{
Ultra-small neonatal dialysis circuits do not maintain safe fluid balance
}

\author{
Malcolm Coulthard ${ }^{1}$ \\ Received: 20 January 2016 / Accepted: 27 January 2016/Published online: 26 February 2016 \\ (C) IPNA 2016
}

Nishimi and colleagues have designed a renal replacement device for tiny babies in which the extracorporeal circuit volume (ECV) is "ultra-small" at only $3.2 \mathrm{ml}$, by just using one operating syringe [1]. They note that their current system does not maintain fluid balance "accurately", but that they "are working on" this "serious weakness". Unfortunately, they will not be able to regulate the ultrafiltration rate without adding extra components to the circuit. This is because water moves across a dialyser according to the transmembrane pressure (TMP), and this cannot be regulated while the filter is exposed to the pressures in the blood access or return lines.

In their earlier (manual) circuit design, the proximal operating syringe created a positive TMP by pushing blood through the dialysis filter, and generated a mean daily ultrafiltrate of $40 \mathrm{ml}$ (abstracted from their Figure 5a). Their new (automated) circuit uses a distal syringe to draw blood through the filter, which generates a negative TMP that drew a mean of $112 \mathrm{ml} /$ day of water into the blood (range 16 to $260 ; P=0.02$, one-sample $t$ test; Figure 5b). Large, unpredictable fluid shifts like this could harmfully overload small infants, most of whom are fluid-replete when they commence renal replacement therapy.

Two ways of isolating the dialysis filter pressure from the rest of the blood circuit include using a valve and second syringe, as we have done in the Nidus [2], and generating a

Malcolm Coulthard

malcolm.coulthard@nuth.nhs.uk

1 Department of Paediatric Nephrology, Great North Children's Hospital, NE1 4LP Newcastle, UK
TMP by using a computer-controlled intermittent isolation valve distally. The latter requires a pressure transducer in the circuit, and a method of continuously measuring the ultrafiltration rate to provide feed-back to the computer algorithm. So far, devices that use this approach cannot produce precise fluid control; the Prismaflex is inaccurate by $\pm 30 \mathrm{ml} / \mathrm{h} \mathrm{[3]}$, and the CARPEDIEM by $\pm 7.5 \%$ of the dialysate fluid flow, despite weighing its ultrafiltrate to the nearest gram [4]. All methods of controlling fluid balance inevitably increase the ECV, which makes safe "ultra-small" renal replacement devices difficult to build.

\section{Compliance with ethical standards}

Conflicts of interest The author declares no conflicts of interest.

\section{References}

1. Nishimi S, Ishikawa K, Sasaki M, Furukawa H, Takada A, Chida S (2015) Ability of a novel system for neonatal extracorporeal renal replacement therapy with an ultra-small volume circuit to remove solutes in vitro. Pediatr Nephrol 31:493-500

2. Coulthard MG, Crosier J, Griffiths C, Smith J, Drinnan M, Whitaker M, Beckwith R, Matthews JN, Flecknell P, Lambert HJ (2014) Haemodialysing babies weighing $<8 \mathrm{~kg}$ with the Newcastle infant dialysis and ultrafiltration system (Nidus); comparison with peritoneal and conventional haemodialysis. Pediatr Nephrol 29:1869-1871

3. Diaa M (2013) Prismaflex user manual. http://www.scribd.com/doc/ 141000459/Prismaflex-user-manual

4. Ronco R, Garzotto F, Brendolan A, Zanella M, Bellettato M, Vedovato S, Chiarenza F, Ricci Z, Goldstein SL (2014) Continuous renal replacement therapy in neonates and small infants: development and first-in-human use of a miniaturised machine (CARPEDIEM). Lancet 383:1807-1813 